\title{
Rotational Spectroscopy of $\mathrm{ClZnCH}_{3}\left(X^{1} \mathrm{~A}_{1}\right)$ :
}

\section{Gas-phase Synthesis and Characterization of a Monomeric Grignard-Type Reagent}

\author{
J. Min, M. P. Bucchino, K. M. Kilchenstein, \\ and \\ L. M. Ziurys* \\ Department of Chemistry and Biochemistry \\ Department of Astronomy \\ Steward Observatory, 933 North Cherry Avenue, University of Arizona, Tucson, AZ 85721, \\ USA \\ * Corresponding author: L. M. Ziurys, 1ziurys@email.arizona.edu, Fax 520-621-1532
}

39

40

41

42

43 


\section{Introduction}

Interest in organozinc halides (RZnX) has existed for well over a century, beginning with the synthesis of EtZnI in 1864 [1]. Such compounds have many versatile applications, particularly in organic synthesis but also in polymer chemistry [e.g. 2, 3]. Their high chemoselectivity and functional group tolerance makes them excellent synthetic reagents. For example, in the Barbier reaction, the nucleophilic addition of the alkyl group across a carbonyl bond occurs through the intermediate XZnR [4]. The Reformatsky process converts an $\alpha$ haloester and ketone or aldehyde into a $\beta$-hydroxyester with an organozinc reagent, the "Reformatsky enolate" [5]. Organozinc halides have also been found to react with aryl isocyanates to yield the corresponding $N$-substituted carbamates [6], and have been successfully employed in the total synthesis of natural products such as indoles [7] and polycyclic ethers [8]. Because the organozinc species easily undergo transmetalation, they are ideal reagents for crosscoupling reactions, as well. One of the most versatile schemes of this type in contemporary organic synthesis is the Negishi coupling, which forms carbon-carbon bonds from an organic halide and an organozinc halide in the presence of a nickel or palladium catalyst. The exact mechanism of the Negishi coupling has not yet been determined, however.

Because of their widespread chemical use, there have been various structural studies of alkyl zinc halides. Crystal structures have been determined for several ethyl compounds of this type, including EtZnCl, EtZnI, and the monomeric adduct EtZnCl,TMEDA [9,10,11]. Such species have shown to exhibit sheet and "wavy-sheet"-like geometries or a distorted tetrahedron, as for the adduct compound. Theoretical studies $[12,13]$ have focused on $\mathrm{CH}_{3} \mathrm{ZnX}$ as a model system to probe, for example, the transmetalation step and its cis-trans isomerization in the Negishi reaction [14]. Theoretical calculations suggest these compounds have linear X-Zn-C 
backbones, and thus are "symmetric tops". Gas-phase spectroscopy has also been carried out for one alkyl zinc species, $\mathrm{IZnCH}_{3}$. The pure rotational spectrum of this molecule, including various isotopically-substituted species, has been measured by the Ziurys group, who established the first experimental structure of a monomeric alkyl zinc halide compound [15]. Previous to this work, the rotational spectrum of the zinc insertion product, $\mathrm{HZnCH}_{3}$, was also recorded [16].

Measurement of various isotopologues of this species also resulted in the determination of its structure. Surprisingly, $\mathrm{IZnCH}_{3}$ and $\mathrm{HZnCH}_{3}$ have remarkably similar, $\mathrm{C}_{3 v}$ geometries, despite the large size difference between the hydrogen and iodine atoms.

Here we present the first gas-phase observation and spectroscopic characterization of monomeric $\mathrm{ClZnCH}_{3}$. Pure rotational spectra of this molecule in the main zinc isotope, $\mathrm{Cl}^{64} \mathrm{ZnCH}_{3}$, and two other $\mathrm{Zn}$ isotopologues $\left(\mathrm{Cl}^{66} \mathrm{ZnCH}_{3}, \mathrm{Cl}^{68} \mathrm{ZnCH}_{3}\right)$, were measured in their natural abundances using both millimeter-wave direct absorption and Fourier transform microwave (FTMW) techniques. The obvious K-ladder structure found in spectra indicates this species exhibits $\mathrm{C}_{3 \mathrm{v}}$ symmetry, as predicted by theory. Quadrupole hyperfine splittings arising from the ${ }^{35} \mathrm{Cl}$ nucleus were also resolved in the FTMW data, providing insight into the $\mathrm{Zn}-\mathrm{Cl}$ bond. In this paper we present our measurements, spectroscopic analysis, and preliminary structure of $\mathrm{ClZnCH}_{3}$ in monomeric form.

\section{Experimental}

Two complimentary instruments of the Ziurys group were used to record the gas-phase rotational spectrum of $\mathrm{ClZnCH}_{3}$ : a millimeter/sub-mm direct absorption spectrometer and a FTMW system. The direct absorption spectrometer consists of a three basic parts: a tunable, coherent source of $\mathrm{mm} / \mathrm{sub}-\mathrm{mm}$ radiation, a stainless steel reaction cell containing a Broida-type oven, and a detector. The radiation source is a suite of phase-locked Gunn oscillator/varacter 
multiplier combinations, covering the range $65-850 \mathrm{GHz}$. The double-pass reaction cell is coupled with a Roots-type blower pumping system, while the detector is a helium-cooled InSb hot-electron bolometer. Radiation from the source is quasi-optically propagated through the cell and into the detector through a series of optical elements. Phase-sensitive detection is carried out by frequency modulation of the radiation source. Signals from the InSb detector are processed by a lock-in amplifier at twice the frequency modulation rate, resulting in second derivative line profiles. Transition frequencies were measured from scans $5 \mathrm{MHz}$ in width, fit with Gaussian profiles. The measurement uncertainty is estimated to be $\pm 50 \mathrm{kHz}$. For more details, see ref. [17].

The FTMW spectrometer is a Balle-Flygare-type instrument consisting of a vacuum chamber that houses a Fabry-Pérot cavity with two spherical aluminum mirrors in a nearconfocal arrangement [18]. For $4-40 \mathrm{GHz}$ operation, the frequency source is a synthesizer (Agilent), and the detector is a low noise amplifier (Miteq or Spacek). Molecules are introduced into the chamber by a pulsed supersonic nozzle (General Valve), oriented $40^{\circ}$ relative to the optical axis and operating at $10 \mathrm{~Hz}$. Radiation at a given frequency is pulsed into the cavity, which has an instantaneous bandwidth of about $600 \mathrm{kHz}$, from an antenna imbedded in one mirror. If there is a resonant transition, molecules created in the jet absorb the radiation and their subsequent emission is detected by a low-noise amplifier as a function of time, the Free Induction Decay (FID). Frequency domain spectra are then generated with $2 \mathrm{kHz}$ resolution by a Fast Fourier transform (FFT). More details can be found in [18].

$\mathrm{ClZnCH}_{3}$ was created in both systems in the gas phase in a DC discharge from the reaction of zinc vapor and $\mathrm{CH}_{3} \mathrm{Cl}$ in the presence of argon gas. For the mm-wave spectrometer, zinc vapor was generated by heating metal pieces in a Broida-type oven. About $20-30$ mTorr of 
$\mathrm{CH}_{3} \mathrm{Cl}$ vapor was introduced to the cell directly above the oven. In addition, about 15 mTorr of argon was added from underneath it and also flowed over the back lens of the spectrometer to prevent metal coating. The discharge was sustained directly over the oven.

In the FTMW system, the molecule was created using the Discharge Assisted Laser Ablation Source (DALAS) of the Ziurys group; see ref. [19]. A mixture of $0.2-0.5 \% \mathrm{CH}_{3} \mathrm{Cl}$ in argon gas was pulsed through a supersonic nozzle into the cell with a backing pressure of 40 psi. Zinc vapor was generated by laser ablation of a translating, rotating metal rod using the second harmonic of Nd:YAG laser (Surelite II), and added to the mixture in the supersonic expansion. A relatively low DC discharge of $600 \mathrm{~V}$ was then applied to the expanding gas. $\mathrm{ClZnCH}_{3}$ was not observed when the discharge was higher than $800 \mathrm{~V}$. The pulse valve was opened for $750 \mu \mathrm{s}$ and the discharge applied for $990 \mu$ s thereafter. Typically 1000 - 5000 shots were averaged to achieve a satisfactory signal-to-noise ratio. All spectra are recorded as Doppler doublets; the average of these doublets is the measured transition frequency.

\section{Results and Analysis}

The search for $\mathrm{ClZnCH}_{3}$ was initially conducted with the millimeter wave spectrometer. Based on the previous studies of $\mathrm{IZnCH}_{3}$ and $\mathrm{HZnCH}_{3}$, it was assumed that the molecule would have $\mathrm{C}_{3 \mathrm{v}}$ symmetry, and a rotational constant of $B=2429 \mathrm{MHz}$ was estimated, scaled from those of the iodine and hydrogen analogs. A frequency range of 260-292 GHz was continuously scanned, resulting in the identification of two very similar spectral patterns, each exhibiting the classic symmetric top signature with a $B$ constant near the predicted value. The two patterns had a relative intensity ratio of $1: 0.56$, close to that of the two most abundant zinc isotopes ${ }^{64} \mathrm{Zn}$ and ${ }^{66} \mathrm{Zn}$. Removal of the zinc vapor caused the signals to disappear, indicating that they were indeed arising from $\mathrm{Zn}$-bearing species. These two sets of transitions were then identified as $\mathrm{Cl}^{64} \mathrm{ZnCH}_{3}$ 
and $\mathrm{Cl}^{66} \mathrm{ZnCH}_{3}$. By searching nearby frequency ranges, symmetric top patterns arising from $\mathrm{Cl}^{68} \mathrm{ZnCH}_{3}$ were also found. Contamination from $\mathrm{CH}_{3} \mathrm{Cl}$ was a common problem.

Once spectral constants were established from the mm-wave data, searches for $\mathrm{Cl}^{64} \mathrm{ZnCH}_{3}, \mathrm{Cl}^{66} \mathrm{ZnCH}_{3}$ and $\mathrm{Cl}^{68} \mathrm{ZnCH}_{3}$ were conducted using the FTMW system in the frequency range 10-31 GHz. Lines for the three species were readily found, all exhibiting quadrupole hyperfine structure attributable to the ${ }^{35} \mathrm{Cl}$ nucleus of $\mathrm{I}=3 / 2$. These measurements confirmed that the molecule contained chlorine, lending further credence to the identification. Only the stronger hyperfine transitions were measured.

Figure 1 displays spectra of the $K=0$ through $K=6$ components of the $J=58 \leftarrow 57$ rotational transition of $\mathrm{Cl}^{64} \mathrm{ZnCH}_{3}$, recorded with the mm-wave spectrometer near $296 \mathrm{GHz}$. Although there are strong lines arising from methyl chloride in the spectrum, the distinctive $K$ component progression of a symmetric top is clearly visible in the data, with the lines having a relative frequency spacing of 1:3:5:7 ... The $K=3$ and 6 components also appear roughly a factor of 2 greater in intensity relative to adjacent $K$ components, resulting from nuclear spin statistics due to exchange of the three identical protons $(I=1 / 2)$ upon rotation of the methyl group about the $\mathrm{C}_{3}$ axis [20]. There is no evidence of chlorine quadrupole structure in these data, as expected at higher $J$ transitions of a closed-shell molecule. The species clearly has $\mathrm{C}_{3 \mathrm{v}}$ symmetry with a ${ }^{1} \mathrm{~A}_{1}$ ground electronic state.

Representative FTMW spectra of $\mathrm{Cl}^{64} \mathrm{ZnCH}_{3}$ are shown in Figure 2. Here chlorine hyperfine components, labeled by quantum number $F$, are displayed, arising from the $K=0$ and 1 components of the $J=3 \rightarrow 2$ transition near $15 \mathrm{GHz}$. There is a frequency break in the figure to show multiple lines. Each feature consists of Doppler doublets, as indicated by brackets on the spectrum. The $F=9 / 2 \rightarrow 7 / 2$ and $F=7 / 2 \rightarrow 5 / 2$ components for $K=0$ are within $4 \mathrm{kHz}$ of each 
other, and are almost totally collapsed. There may be a hint of a shoulder to higher frequency on the measured line. For $K=1$, these two components are separated by about $1.7 \mathrm{MHz}$, as expected. The weaker $F=5 / 2 \rightarrow 3 / 2$ transition is also visible in both $K$ ladders. The hyperfine patterns will vary according to the value of $K$, as the quadrupole energies scale by the factor 1 $3 K^{2} / J(J+1)[20,21]$.

As shown in Table 1, a total of 7 to 10 rotational transitions $J+1 \leftrightarrow J$ were recorded for $\mathrm{Cl}^{64} \mathrm{ZnCH}_{3}, \mathrm{Cl}^{66} \mathrm{ZnCH}_{3}$, and $\mathrm{Cl}^{68} \mathrm{ZnCH}_{3}$, respectively, each consisting of several $K$ components. For the mm-wave data, typically $K=0$ through 6 components were recorded, but severe contamination by $\mathrm{CH}_{3} \mathrm{Cl}$ often limited the frequency coverage. For the FTMW data, only the $K=$ 0 and 1 lines were measured, each consisting of multiple hyperfine components whose pattern varies with $K$, as mentioned. Note that for all three zinc isotopologues, hyperfine splittings arising from the chlorine nucleus produce a similar pattern. A total of 119 individual frequencies were recorded, 33 from the FTMW spectrometer and the remainder with the mm-wave instrument.

The transitions frequencies for $\mathrm{Cl}^{64} \mathrm{ZnCH}_{3}, \mathrm{Cl}^{66} \mathrm{ZnCH}_{3}$ and $\mathrm{Cl}^{68} \mathrm{ZnCH}_{3}$ were analyzed individually with a symmetric top Hamiltonian using the non-linear least square routine SPFIT [22]. The data were weighted according to the instrumental uncertainty: $\pm 50 \mathrm{kHz}$ for the mmwave data and $\pm 2 \mathrm{kHz}$ for the FTMW frequencies, respectively. From this analysis, rotational, centrifugal distortion and electric quadrupole hyperfine terms were determined, and are presented in Table 2. Because transitions were measured only within $K$ ladders, the parameters $B, D_{J}, D_{J K}$, and the sixth order centrifugal distortion term $H_{J K}\left(\mathrm{Cl}^{66} \mathrm{ZnCH}_{3}\right.$ and $\mathrm{Cl}^{66} \mathrm{ZnCH}_{3}$ only $)$ could be determined for each isotopologue, but not $A$ or $D_{K}$, as defined below in the energy level expression $[20,21]$ 


$$
F(J, K)=B J(J+1)-D_{J} J^{2}(J+1)^{2}+(A-B) K^{2}-D_{J K} J(J+1) K^{2}-D_{K} K^{4}+H_{J K} J^{2}(J+1)^{2} K^{2}
$$

To fit the data, $A$ was fixed to the value measured for $\mathrm{HZnCH}_{3}$ [16].Also, the quadrupole constant $e q Q$ was determined for each zinc species. The rms of the individual fits is in the range of $66-81 \mathrm{kHz}$, which is within the experimental uncertainty.

\section{Discussion}

This study suggests that $\mathrm{ClZnCH}_{3}$ can be formed in the gas phase through the oxidative addition of zinc to chloromethane. The fact that fragment species such as $\mathrm{ZnCH}_{3}$ and $\mathrm{ZnCl}$ were not observed in the mm-wave data, where large frequency regions were scanned, is strong evidence for such facile zinc insertion. The spectra are sufficiently well-known for these two molecules to make their appearance obvious [23, 24]. Furthermore, use of a higher discharge voltage with DALAS resulted in the destruction of $\mathrm{ClZnCH}_{3}$; if the species was created from radical fragments, the higher discharge voltage should enhance the signals. It should be noted that production of $\mathrm{ClZnCH}_{3}$ did require the discharge, which is likely needed to activate the zinc, i.e. promote it into an excited electronic state such as ${ }^{3} \mathrm{P}$ or ${ }^{1} \mathrm{P}[25]$. This result is consistent with theoretical modeling, which predicts that the insertion of zinc into the $\mathrm{C}-\mathrm{Cl}$ bond of $\mathrm{CH}_{3} \mathrm{Cl}$ is exothermic by $29.6 \mathrm{kcal} / \mathrm{mol}$ [12]. However, there is a $44.3 \mathrm{kcal} / \mathrm{mol}$ activation barrier that first must be overcome; hence the need for the discharge. According to theory, the $\mathrm{C}-\mathrm{Cl}$ bond is elongated as the zinc approaches, resulting in a transition state with $\mathrm{C}_{\mathrm{s}}$ symmetry.

Our past studies have suggested that zinc insertion leads to $\mathrm{HZnCH}_{3}$ and $\mathrm{IZnCH}_{3}[15$, 16]. The iodine analog was produced in the mm-wave instrument under very similar conditions to $\mathrm{ClZnCH}_{3}$; however, the signals for $\mathrm{IZnCH}_{3}$ were substantially stronger. This finding likely reflects the relative $\mathrm{C}-\mathrm{Cl}$ and $\mathrm{I}-\mathrm{C}$ bond enthalpies, which are $328 \mathrm{~kJ} / \mathrm{mol}$ and $220 \mathrm{~kJ} / \mathrm{mol}$, respectively $[26,27]$. 
The symmetry of $\mathrm{ClZnCH}_{3}$ is clearly $\mathrm{C}_{3 \mathrm{v}}$. The observed rotational spectrum is unambiguously that of a symmetric top, as found for $\mathrm{HZnCH}_{3}$ and $\mathrm{IZnCH}_{3}[15,16]$. The $\mathrm{Cl}-\mathrm{Zn}-\mathrm{C}$ backbone is linear, as predicted by theory [12]. In contrast, calculations predict that calcium and palladium form insertion products that have a bent backbone [12]. This bent geometry in $\mathrm{ClZnCH}_{3}$ would produce additional splittings generated by asymmetry doubling, which were simply not observed.

Because only the zinc atom was isotopically substituted for $\mathrm{ClZnCH}_{3}$, a full structure cannot be derived. Nevertheless, if the $\mathrm{Zn}-\mathrm{C}$ and $\mathrm{C}-\mathrm{H}$ bond lengths and the $\mathrm{H}-\mathrm{C}-\mathrm{H}$ angle are fixed to the values found for $\mathrm{IZnCH}_{3}$, where isotopic substitutions were carried out for the carbon and hydrogen atoms, the $\mathrm{Zn}-\mathrm{Cl}$ bond distance can be estimated. The bond length was found to be $\mathrm{r}_{\mathrm{Zn}-\mathrm{Cl}}=2.23(7) \AA$. This value is a $\sim 0.1 \AA$ increase from that in the $\mathrm{ZnCl}$ radical, which has $\mathrm{r}_{\mathrm{Zn}-\mathrm{Cl}}=2.133(2) \AA$. It is also somewhat shorter that those found in the crystal structure of $\mathrm{ClZnCH}_{2} \mathrm{CH}_{3}\left(\mathrm{r}_{\mathrm{Zn}-\mathrm{Cl}}=2.3486(6) \AA\right.$ and 2.5408(7) $\AA$ [9]), and that measured for EtZnCl,TMEDA [11] of 2.269(3) A. In these two structures, however, zinc is bonded to four instead of two ligands. In crystalline $\mathrm{ClZnCH}_{2} \mathrm{CH}_{3}$, the zinc atom is tetrahedrally linked to one ethyl and three chloride ligands in an infinite sheet, with two different $\mathrm{Zn}-\mathrm{Cl}$ bonds. In the other complex, the bidendate TMEDA ligand forms the two additional bonds to the central zinc atom. Therefore, it is not surprising that the zinc-chlorine bond lengths vary within these three structures. Note that the sum of the covalent radii of zinc and chlorine yields $2.33 \AA$. Diatomic $\mathrm{ZnCl}$ is likely to be quite ionic. Because its $\mathrm{Zn}-\mathrm{Cl}$ bond length is longer, $\mathrm{ClZnCH}_{3}$ likely has more covalent character relative to the chloride. Ethyl zinc chloride and the TMEDA adduct have longer bond lengths because of steric hindrance.

For $\mathrm{ClZnCH}_{3}, e q Q$ was found to be -27.443 (41) $\mathrm{MHz}$, significantly smaller than that of 
the ${ }^{35} \mathrm{Cl}$ nucleus, which has a value of $-80 \mathrm{MHz}$ [28]. This difference suggests that the molecule also has significant ionic character. Using the Townes and Dailey approximation [21], the fraction of ionic character $\chi$ in the $\mathrm{Zn}-\mathrm{Cl}$ bond can be estimated from the following equation:

$$
\chi=\left(1-\frac{e q Q\left(\mathrm{ClZnCH}_{3}\right)}{e q Q(\mathrm{Cl})}\right) \times 100 \%
$$

For $\mathrm{ClZnCH}_{3}$, the fraction is calculated to be $\chi=65.7 \%$. A comparison with the quadrupole coupling constant for $\mathrm{CH}_{3} \mathrm{Cl}$, eqQ $=-74.7631$ (35) $\mathrm{MHz}$ [28], can also give insight into the relative bonding properties. This value is - 2.7 times greater in magnitude than that of $\mathrm{ClZnCH}_{3}$, and indicates $6.5 \%$ ionic character in the $\mathrm{Cl}-\mathrm{C}$ bond. Clearly, the insertion of zinc substantially increases the ionic properties of the molecule, although not to the degree of $\mathrm{ZnCl}$. The charge distribution in methyl zinc chloride is $\mathrm{Cl}^{\delta-} \mathrm{Zn}^{\delta+}-\mathrm{CH}_{3}$, as predicted for Grignard-type species, e.g. $[4,5]$.

Oxidative addition of a metal to the $\mathrm{C}-\mathrm{Cl}$ bond of $\mathrm{CH}_{3} \mathrm{Cl}$ has been examined using DFT methods in the context of an Activation Strain model by de Jong et al. [12]. These calculations predict that other metals such as $\mathrm{Pd}, \mathrm{Be}$, and $\mathrm{Mg}$ are easier to insert into $\mathrm{C}-\mathrm{Cl}$ bond than $\mathrm{Zn}$. Our experiment thus opens the door to other potential metal insertion products including the gasphase Grignard reagent itself.

\section{Conclusion}

The first study of a Grignard-type reagent in monomeric form, methyl zinc chloride, has been conducted. The pure rotational spectrum demonstrates that the molecule has $\mathrm{C}_{3 \mathrm{v}}$ symmetry with a linear $\mathrm{Cl}-\mathrm{Zn}-\mathrm{C}$ backbone. Based on zinc isotopic substitution, an estimate of the $\mathrm{Zn}-\mathrm{Cl}$ bond length has been derived, which was found to be over 0.1 A shorter than those found in the ethyl zinc chloride, based on crystal structures. The $\mathrm{Cl}$-Zn bond appears to be a mixture of covalent and ionic character. This study demonstrates that gas-phase spectroscopic studies of 
monomeric organic reagents can provide insight into their basic chemical properties. It also suggests that activated zinc can readily insert into the $\mathrm{C}-\mathrm{Cl}$ bond.

Acknowledgements:

This research was supported by NSF Grant CHE-1057924. 


\section{References:}

[1] E. Frankland, B.F. Duppa, J. Chem. Soc. 17 (1864) 29.

[2] H.L. Hsieh, J. Polym. Sci., J.Polym.Sci.A. Polym. Chem. 14 (1976) 379.

[3] J.R. Zhou, G.C Fu, J. Am. Chem. Soc. 125 (2003) 14726.

[4] R. Lasch, M.R. Heinrich, J. Org. Chem. 80 (2015) 10412.

[5] A. Conan, S. Sibille, J. Périchon, J. Org. Chem. 56 (1991) 2018.

[6] H. Yang, D. Huang, K. Wang, C. Xu, T. Niu, Y. Hu, Tetrahedron 69 (2013) 2588.

[7] B.A. Haag, Z. Zhang, J. Li, P. Knochel, Angew. Chem. Int. Ed. 49 (2010) 9513.

[8] I. Kadota, H. Takamura, K. Sato, Y. Yamamoto, J. Org. Chem. 67 (2002) 3494.

[9] A. Guerrero, D.L. Hughes, M. Bochmann, Organometallics 25 (2006) 1525.

[10] P.T. Moseley, H.M.M. Shearer, Chem. Commun. 23 (1966) 876.

[11] P.C. Andrews, C.L. Raston, B.W. Skelton, A.H White, Organometallics 17 (1998) 779.

[12] G.T. de Jong, R. Visser, F.M. Bickelhaupt, J. Organomet. Chem. 691 (2006) 4341.

[13] X. Lin, D.L. Phillips, J. Org. Chem.73 (2008) 3680.

[14] J.A. Casares, P. Espinet, B. Fuentes, G. Salas, J. Am. Chem. Soc. 129 (2007) 3508.

[15] M.P. Bucchino, J.P. Young, P.M. Sheridan, L.M. Ziurys, J. Phys. Chem. A 118 (2014)

11204.

[16] M.A. Flory, A.J. Apponi, L.N. Zack, L.M. Ziurys, J. Am. Chem. Soc. 132 (2010) 17186.

[17] L.M. Ziurys, W.L. Barclay Jr., M.A. Anderson, D.A. Fletcher, J.W. Lamb, Rev. Sci. Instrum. 65 (1994) 1517.

[18] M. Sun, A.J. Apponi, L.M. Ziurys, J. Chem. Phys. 130 (2009) 034309.

[19] M. Sun, D.T. Halfen, J. Min, B. Harris, D.J. Clouthier, L.M. Ziurys, J. Chem. Phys. 133 (2010) 174301. 
[20] W. Gordy, R.L. Cook, Microwave Molecular Spectra, Wiley, New York, 1984.

[21] C.H. Townes, A.L. Schawlow, Microwave Spectroscopy, Dover, New York, 1975.

[22] H.M. Pickett, J. Mol. Spectrosc. 148 (1991) 371.

[23] T.M. Cerny, X.Q. Tan, J.M. Williamson, E.S.J. Robles, A.M. Ellis, T.A. Miller, J. Chem. Phys. 99 (1993) 9376.

[24] E.D. Tenenbaum, M.A. Flory, R.L. Pulliam, L.M. Ziurys, J. Mol. Spectrosc. 244 (2007) 153.

[25] S. Castillo, S. Ramírez-Solís, D. Díaz, E. Poulain, O. Novaro, Mol. Phys. 81 (1994) 825.

[26] B.D. Darwent, Nat. Stand. Ref. Data. Ser., Nat. Bur. Stand. 31 (1970) 1.

[27] C.A. McDowell, B.G. Cox, J. Chem. Phys. 20 (1952) 1496.

[28] L. Stř́iteská, M. Šimečková, P. Kania, P. Musil, L. Kolesniková, J. Koubek, Š. Urban, J. Mol. Struct. 919 (2009) 89. 


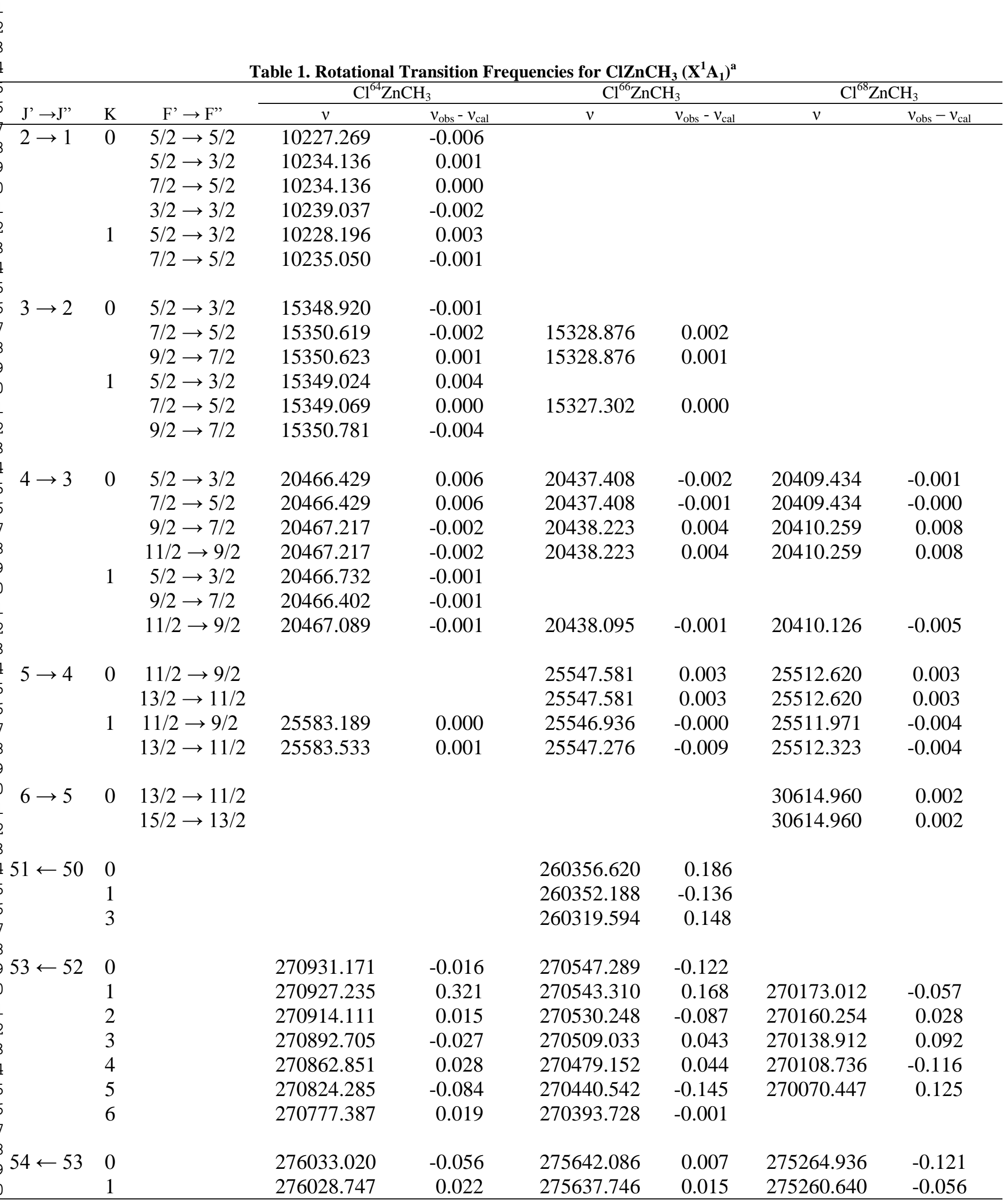

61 


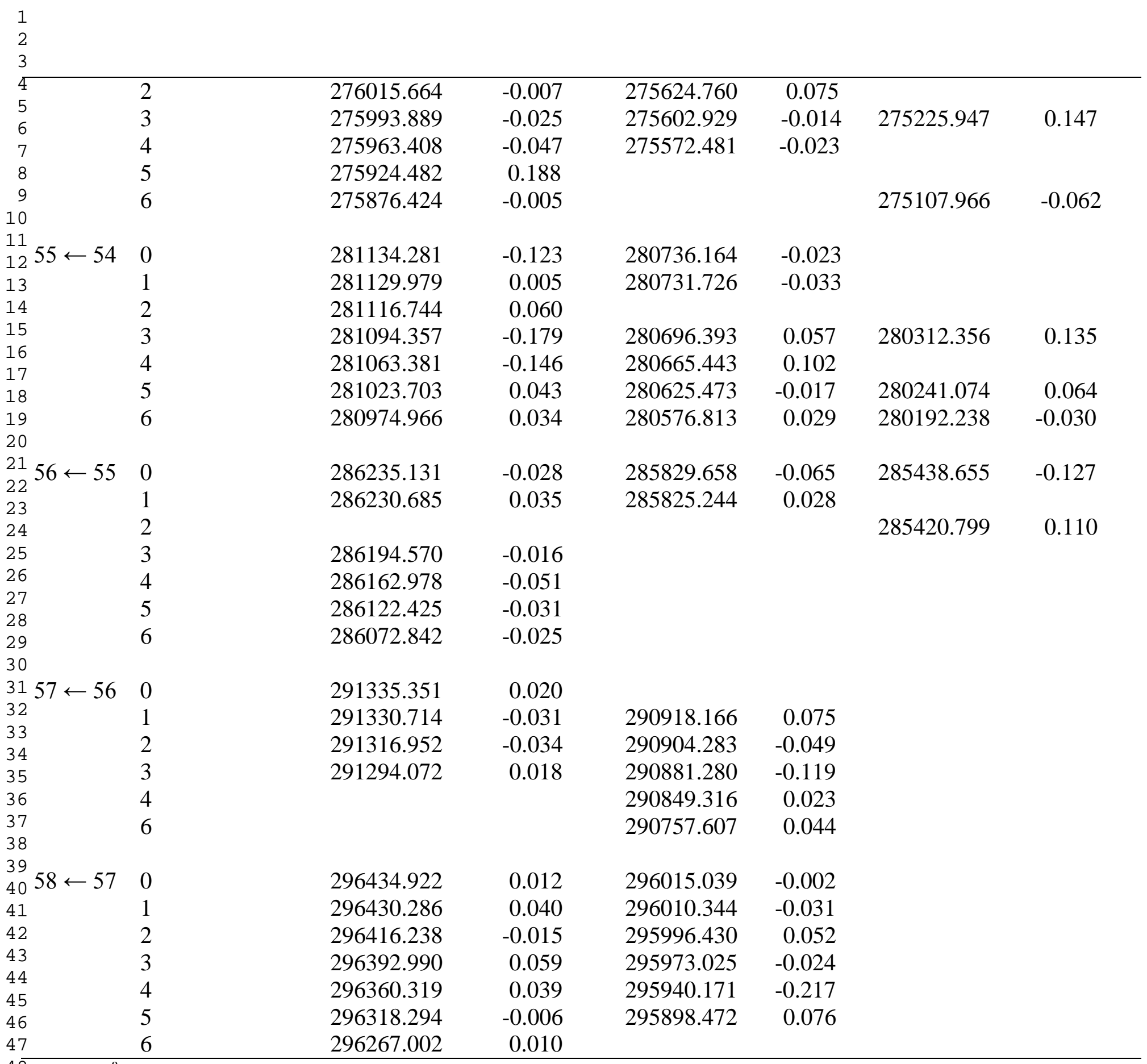


Table 2. Spectroscopic Constants for $\mathrm{ClZnCH}_{3}\left(X^{1} \mathrm{~A}_{1}\right)^{\text {a }}$

\begin{tabular}{cccc}
\hline \multicolumn{4}{c}{} \\
\hline $\mathrm{Cl}$ & $\mathrm{Cl}^{66} \mathrm{ZnCH}_{3}$ & $148000^{\mathrm{b}}$ & $\mathrm{Cl}^{68} \mathrm{ZnCH}_{3}$ \\
\hline $\mathrm{B}$ & $148000^{\mathrm{b}}$ & $2554.76481(66)$ & $148000^{\mathrm{b}}$ \\
$\mathrm{D}_{\mathrm{J}}$ & $2558.39022(56)$ & $0.00043267(12)$ & $2551.26855(61)$ \\
$\mathrm{D}_{\mathrm{JK}}$ & $0.00043354(10)$ & $0.04053(24)$ & $0.00043176(14)$ \\
$\mathrm{H}_{\mathrm{JK}}$ & $0.04081(20)$ & $0.000000046(39)$ & $0.040388(29)$ \\
eqQ & $0.000000089(33)$ & $-27.89(31)$ & -- \\
$\mathrm{rms}$ & $-27.443(41)$ & 0.079 & $-28.14(52)$ \\
\hline
\end{tabular}

${ }^{\text {a. }}$ In $\mathrm{MHz}$; uncertainties are $3 \sigma$

b. Held fixed (see text). 
Table 3. Structures of $\mathrm{HZnCH}_{3}, \mathrm{XZnCH}_{3}$, and Related Compounds

\begin{tabular}{|c|c|c|c|c|c|c|c|}
\hline & $\mathrm{r}_{\mathrm{X}-\mathrm{Zn}}(\AA)$ & $\mathrm{r}_{\mathrm{Zn}-\mathrm{C}}(\AA)$ & $\mathrm{r}_{\mathrm{C}-\mathrm{H}}(\AA)$ & $\angle \mathrm{MCH}(\mathrm{deg})$ & $\angle \mathrm{HCH}(\mathrm{deg})$ & method & ref \\
\hline \multirow{2}{*}{$\mathrm{HZnCH}_{3}$} & $1.5209(1)$ & $1.9281(2)$ & $1.140(9)$ & $110.2(3)$ & $108.7(3)$ & $\mathrm{r}_{0}$ & [16] \\
\hline & 1.533 & 1.954 & 1.098 & 110.7 & & theory, $r_{e}$ & [12] \\
\hline $\mathrm{IZnCH}_{3}$ & $2.4076(2)$ & $1.9201(2)$ & $1.105(9)$ & $110.2(5)$ & $108.7(5)$ & $\mathrm{r}_{0}$ & [15] \\
\hline $\mathrm{ClZnCH}_{3}$ & $\begin{array}{l}2.23(7) \\
2.129\end{array}$ & $\begin{array}{l}1.9201^{\mathrm{a}} \\
1.937\end{array}$ & $\begin{array}{l}1.105^{\mathrm{a}} \\
1.096\end{array}$ & $\begin{array}{l}110.2^{\mathrm{a}} \\
109.6^{2}\end{array}$ & $108.7^{\mathrm{a}}$ & $\begin{array}{c}\mathrm{r}_{0} \\
\text { theory, } \mathrm{r}_{\mathrm{e}}\end{array}$ & $\begin{array}{c}\text { This } \\
\text { work } \\
{[12]}\end{array}$ \\
\hline $\mathrm{ClZnCH}_{2} \mathrm{CH}_{3}{ }^{\mathrm{b}}$ & $\begin{array}{l}2.5408(7) \\
2.3486(6)\end{array}$ & & & & & & [9] \\
\hline ClZnEtTMEDA $^{\mathrm{b}}$ & $2.269(3)$ & & & & & & [11] \\
\hline $\mathrm{ZnCl}$ & $2.133(2)$ & & & & & $\mathrm{r}_{0}$ & [24] \\
\hline
\end{tabular}

a. Fixed.

b. X-ray crystal structure. 
Figure 1: Millimeter-wave spectrum of $\mathrm{Cl}^{64} \mathrm{ZnCH}_{3}\left(\mathrm{X}^{1} \mathrm{~A}_{1}\right)$, showing the $K$ components of the $J$ $=58 \leftarrow 57$ transition near $296 \mathrm{GHz}$. Contaminating lines arise from $\mathrm{CH}_{3} \mathrm{Cl}$. The relative frequency spacing of the components $(K=0-6)$, as well as their relative intensities, indicates that the molecule is clearly a prolate symmetric top with $\mathrm{C}_{3 \mathrm{v}}$ symmetry. This spectrum is created from two $110 \mathrm{MHz}$ wide scans, each acquired in $\sim 70 \mathrm{~s}$.

Figure 2: FTMW spectrum of the $J=3 \rightarrow 2$ rotational transition of $\mathrm{Cl}^{64} \mathrm{ZnCH}_{3}$, showing the ${ }^{35} \mathrm{Cl}$ hyperfine lines arising from quadrupole coupling in the $K=0$ and 1 components, labeled by the quantum number $F$. Doppler doublets are indicated on the figure by brackets. There is one frequency break in the spectrum in order to show multiple lines. The $F=9 / 2 \rightarrow 7 / 2, F=$ $7 / 2 \rightarrow 5 / 2$, and $F=5 / 2 \rightarrow 3 / 2$ hyperfine components are present for both $K=0$ and 1 , although in some case they are blended. Each spectral feature was acquired in one, $600 \mathrm{kHz}$-wide scan, averaged over 2500 shots, and cropped to show the given frequency range. 


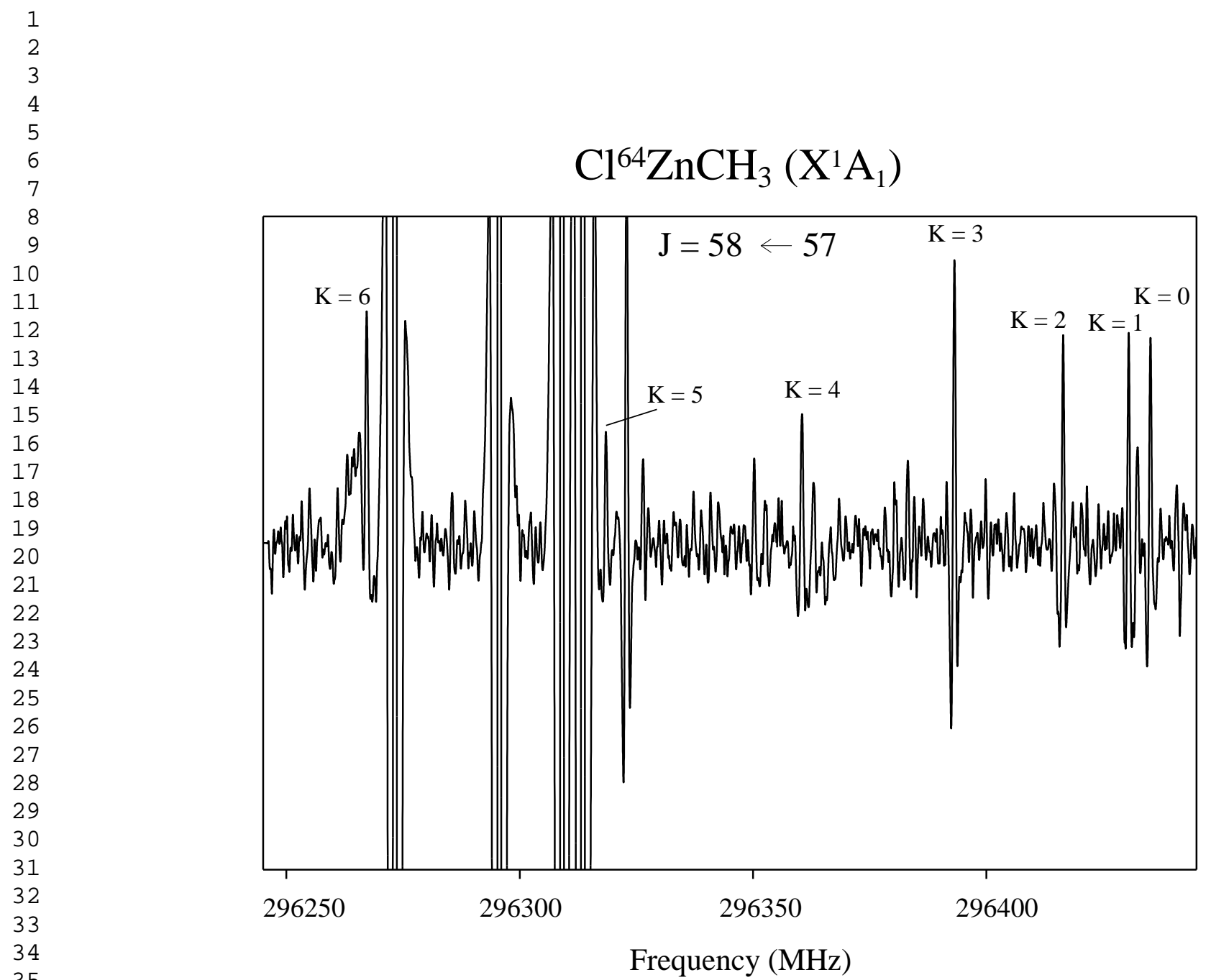

Figure 1 


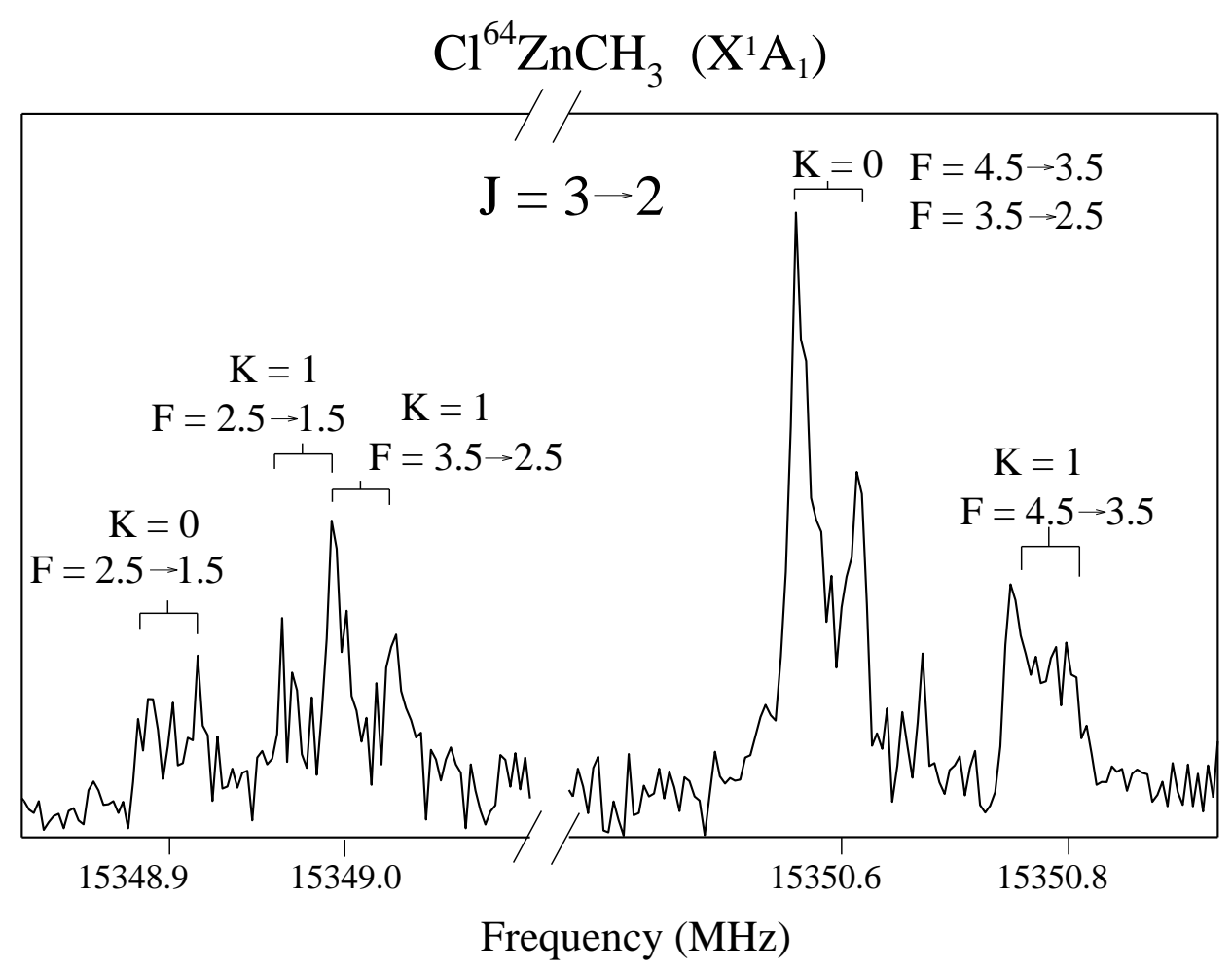

Figure 2 


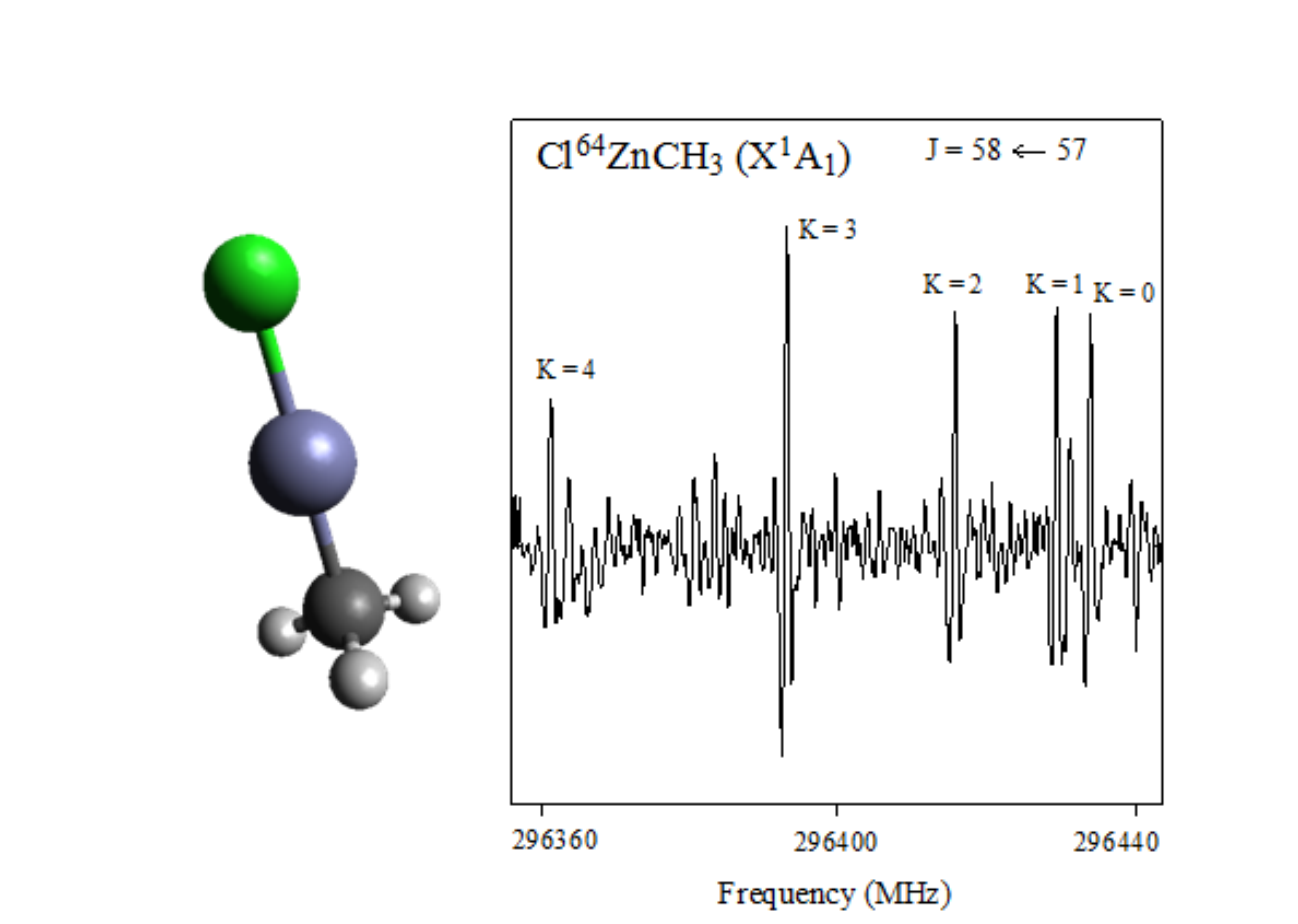

